\title{
Digital Storytelling: A Video-based Approach for Engaging University Students in Health Education
}

\author{
Shaimaa Abdel-Aziz ${ }^{1 *(\mathbb{D})}$, Yasmine Samir Galal', Salah Hassan Al Hanafy ${ }^{2}$, Mohamed Ghamrawy ${ }^{2}$, Dina Samy Mohamed Shaheen ${ }^{3}$ \\ ${ }^{1}$ Department of Public Health and Community Medicine, Kasr Al-Ainy Faculty of Medicine, Cairo University, Cairo, Egypt; \\ ${ }^{2}$ Communication for Development, United Nations Children Fund, Cairo, Egypt; ${ }^{3}$ Department of Medicine, Kasr Al-Ainy Faculty \\ of Medicine, Cairo University, Cairo, Egypt
}

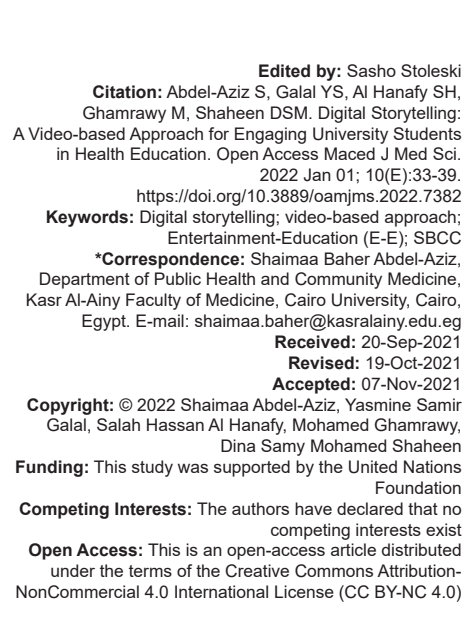

\section{Abstract}

BACKGROUND: Digital stories are short videos that use narrative structures to address health outcomes from a personal perspective.

AIM: The main objective of this study was to train university students to design a video-based health education program for promoting peer-to-peer education and community awareness.

METHODS: Cross-sectional study. The study was conducted as a project for medical students, enrolled in the implementation of the Egyptian Youth Initiative (EYI), executed in response to the Government of Egypt- United Nations Children's Fund (UNICEF) Country Program of Cooperation for 2016 - 2018. A four-day train-the-trainer workshop established for capacity building on DST and video communication.

RESULTS: Between June 2017 and May 2018, 120 eligible students were enrolled, among whom median age was 21 years and 67 (55\%) were female. Pre- and posttests detected increased percent change of students' knowledge regarding different health issues. Open-ended questions highlighted pros and cons of the program, the most important skills and knowledge gained, suggestions and recommendations mentioned by the students to maximize the use of this type of workshops in the framework of strengthening and activating the initiative outcome. The trainer created a grading rubric to evaluate student's video projects.

CONCLUSION: The digital story is a lay method to capture meaningful, impactful stories that can be used to advocate for public health concerns and crises. The study highlights the need for high-quality research on the impact of DST in health professionals' education and behaviors.

\section{Introduction}

Media and digital technology are shaping current approaches for teaching and learning. COVID-19 pandemic is causing severe damage to the health care system, the economy, and society as a whole. The development of information and technology, digital media plays a pivotal role in this pandemic, especially in the use of visual data to disseminate information, mobile health (mHealth) to coordinate medical resources, and social media to promote public health campaigns [1].

Digital storytelling (DST) is a creative technology tool used in school, college, university and community-based settings, and multidisciplinary fields such as education, counseling, medicine, nursing, and public health [2], [3]. In DST, students, research participants, or patients present an issue from a personal perspective using photos, pictures, videos, audio recordings and music, which may enhance active learning, creativity, empowerment and critical thinking skills. It has also been found to accelerate students' comprehension, written skills and vocabulary development [4].
DST has the potential to connect students globally enabling them to learn and share different topics, which would transform the local education pattern to global citizen education [5]. Emerging technology including mobile and online education platforms presents new opportunities for the dissemination of video-based health education [6]. The World Health Organization has identified Health Information Technology (HIT) as a tool with which to address health problems and transform quality of life [7]. With use of the smart phones by general public increasing day by day, an important way of use of HIT is popularization of emojis, images, and icons are pictorial methods of expression as health-related communication.

Along these lines, public health-oriented DST projects have been used as innovative means for community health advocacy for health promotion and disease prevention campaigns (public campaigns on COVID-19 prevention) [8], population health empowerment [9], and raising awareness about cultural values and health care [10]. Universities have proceeded with technologies that provide resources and infrastructure for implementing DST as a teaching and learning tool, which has been found to promote 
student-centered learning, project-based learning, and student engagement in community issues [11], [12].

DST could be used in teaching theories and models for health promotion of undergraduate students. Despite being a valuable tool to improve communication skills and enhance the understanding of health promotion in practice [13], its applications for undergraduate students are still limited [14]. One approach to train our future doctors to pursue lifelong-learning is by acquiring self-directed learning (SDL) skills. SDL is widely used in medical education for the medical graduates to continuously improving their skills and knowledge [15].

The main objective of this study was to train university students to design a video-based health education program for promoting peer-to-peer education and community awareness.

\section{Methods}

\section{Study design and setting}

This cross-sectional study was conducted between June 2017 and May 2018, as a project for medical students enrolled in the Egyptian Youth Initiative (EYI) executed in response to the Government of Egypt-United Nations Children's Fund (UNICEF) Country Program of Cooperation for 2016-2018. The National Population Council (NPC) adopted the EYI aiming for youth empowerment to understand their society's challenges and determine their role in overcoming these challenges. The initiative endorse the objectives of the National Population Strategy 2015-2030 [16] and the United Nations Development Assistance Framework (UNDAF) Program Component Results (PCRs) 1, 3, 4 \& 5 (UNDP 2013-2018) [17]. Fifteen governorates (districts [red zones]/villages), 12 universities, and faculties included in fase one of the initiative. (Supplementary file)

\section{Study population and sampling}

A convenient sample of 120 medical students who are members of International Federation of Medical Students Association (IFMSA) was selected for the study [18]. Ten students were proportionally selected from the 12 universities included in phase one of the initiative.

\section{Study phases and implementation}

\section{Four days' workshop}

A 4-day train-the-trainer workshop has been established by a communication for development UNICEF specialist for capacity building in DST and video production under the supervision of NPC/UNICEF/EYI executive team. It was conducted in the period from September-October 2017.

On the $1^{\text {st }}$ day, objectives and purpose of the workshop were highlighted in the introduction ceremony. After a pretest assessment, students learned how to conduct a community-based structured interview and use tools for rapid community needs assessment. They were provided with knowledge regarding some health population issues. Training package included topics regarding healthy life style, nutrition, family health, and diseases. The topics addressed were: mal-nutrition, iron deficiency anemia, obesity, smoking, female genital mutilation, positive parenting, human immune deficiency virus (HIV), premarital counseling, diabetes, hypertension, breast cancer screening, and hepatitis C.

They understood how social and health problems interact together to affect the entire population and they were motivated to take a role to positively change. They were trained the concept of telling complete story using photography and producing a high quality video report with the least resources (one-man show using their own smart phone). In addition, trainees were provided with the basic knowledge (photography/video training) for producing a video through interactive activities including practice and reviewing do-s and don't-s of data.

On the $2^{\text {nd }}$ day, students learned the capacity to carry out video documentation of the implemented activities and projects and trained to produce their mobile video through three broad processes (plan it- film it -cut it).

On the $3^{\text {rd }}$ day, they understood the concept of Human-centered design (HCD) approach in designing their messages, short clips, or photo essays (communication skills and story- telling). HCD approach includes designing content that is accessible and relevant to the needs of the target population. Students learned also selected individual, interpersonal, community level, Social Behavioral Communication Change (SBCC) [19] theories and models. Students had the flexibility to apply their theory or model in designing their health promotion topic, or to the development of health education message in their projects. Examples of the theoretical applications in health promotion practice are illustrated in Table 1 . Then, students were grouped into 12 teams (12 working groups/10 students from each university) to start their role-play activity. The materials needed to complete the role plays were photos, video clips, and audio clips, songs in digital format, microphones, and editing software such as iMovie, Windows Movie Maker, or iPhoto.

Table 1: Selected theories and models from health promotion undergraduate theory course

\begin{tabular}{ll}
\hline Level & Theory or model \\
\hline Individual & $\begin{array}{l}\text { Health belief model trans theoretical model theory of reasoned action and } \\
\text { planned behavior }\end{array}$ \\
$\begin{array}{ll}\text { Interpersonal } & \text { Social cognitive theory social support clinician-patient communication } \\
\text { Community } & \text { Social ecological model precede-proceed model }\end{array}$ \\
\hline
\end{tabular}


On the $4^{\text {th }}$ day, each group presented their work and feedback was discussed (positive and negatives comments) from the consultant and training team. Students learned how to share their products using social media (EYI branded website, Facebook page, you tube channel, phone App).

Each team was asked to select one topic regarding those included in the training package that addressed main health/health-related problems as identified by the Egyptian Demographic Health Survey (EDHS, 2014) [20] and assigned to put a plan for their field work video projects in their communities.

All students presented their own action plan and succeeded in formulating their own topic goal and objectives. They were highly motivated as many of them extended the peer group to include club and school peers (especially topic directed to adolescent) and a target ranging from 100 to 1000 . They were delighted to apply IEC material in awareness sessions and properly invested the growing role of social media between youth. Before the closing ceremony of the workshop students were assessed through a post-test for gaining knowledge, concerning the topics included in the training package.

\section{Post workshop support and follow-up activity}

Following the 4-day workshop, the specialist was available for post-workshop support and follow-up (online, what's app group and telephone) to be sure of practices, progress and solve any technical problems faced. Furthermore, to discuss their project outlines, video clips, and review the draft of their final video product before presentation. After finishing the field work (3 months later), a 1-day workshop has been held at NPC, attended by 12 IFMSA members' representatives of universities' teams to present their final video project. The consultant's observations have been reported using the rubric evaluation. A guideline to measure the determined criteria of the work done by the students and to provide feedback based on the attributes in the evaluation rubric (Table 2).
The workshop analyzed the range of video products that are commonly used for; documentation, advocacy, experience-sharing within and outside the community. Using a mix of theoretical and hands-on activities, students experienced the challenges and issues faced in producing their videos. The workshop was not intended to prepare the group members to produce a professional video, but to make a good and acceptable video production and move on to the next level in the initiative.

\section{Data management and statistical analysis}

The data were entered and analyzed using (Statistical Package for Social Science IBM version 21) [21] Pre/post-test scored one for the right answer, while wrong answer or do not know received nil. Quantitative data were presented as mean and standard deviation. Frequencies and percentage were used for qualitative variables. Openended questions were analyzed, and information obtained was compiled in a comprehensive manner to highlight the pros and cons of the program, most important skills and knowledge gained by the students.

\section{Ethical considerations}

The executive board of the Egyptian youth initiative (NPC and UNICEF) approved the study as a part of the project framework activity. Verbal consents obtained from all the participants in the study and data confidentially preserved according to the revised Helsinki decelerations of biomedical ethics [22]

\section{Results}

\section{Participant demographics}

One hundred twenty medical students who are members of IFMSA attended and actively participated

Table 2: Specialist grading rubric for digital storytelling project

\begin{tabular}{|c|c|c|c|}
\hline Selection of theory or model 5 points & $\begin{array}{l}\text { Chooses appropriate theory/model, provides strong } \\
\text { justification of use versus another one. } 3-5 \text { points }\end{array}$ & $\begin{array}{l}\text { Chooses appropriate theory/model. Unclear } \\
\text { description and justification of theory/model. 1-3 } \\
\text { points }\end{array}$ & $\begin{array}{l}\text { Fails to provide any description of } \\
\text { theory/model. } 0 \text { points }\end{array}$ \\
\hline Target population 5 points & $\begin{array}{l}\text { Thorough description, statistics, and justification of } \\
\text { choice. } 4-5 \text { points }\end{array}$ & $\begin{array}{l}\text { Partial/incomplete description and unclear } \\
\text { justification of choice. } 1-3 \text { points }\end{array}$ & $\begin{array}{l}\text { Fails to provide any description. } \\
0 \text { points }\end{array}$ \\
\hline Major audiences 3 points & $\begin{array}{l}\text { Thorough description, identifies audiences directly } \\
\text { and indirectly impacted by issue. } 2-3 \text { points }\end{array}$ & $\begin{array}{l}\text { Partial/incomplete description and unclear. } 1 \\
\text { point }\end{array}$ & $\begin{array}{l}\text { Fails to provide any description. } \\
0 \text { points }\end{array}$ \\
\hline Technical skills 9 points & $\begin{array}{l}\text { Organized, nose room, head room, rule of third, } \\
\text { angles, size of Frame. } 6-9 \text { points }\end{array}$ & $\begin{array}{l}\text { Not organized, nose room, head room, rule of } \\
\text { third, angles, size of Frame. } 3-6 \text { points }\end{array}$ & $\begin{array}{l}\text { Poorly disorganized, Angles, size } \\
\text { of frame, Transition and Scenes } \\
\text { Linking } 0 \text { points }\end{array}$ \\
\hline $\begin{array}{l}\text { Storyline, Characters, educational structure } \\
\text { and philosophy of the drama } 10 \text { points }\end{array}$ & $\begin{array}{l}\text { Clear, correct applies theory/model constructs, } \\
\text { emotional appeal, applies to target population, issue, } \\
\text { setting. 8-10 points }\end{array}$ & $\begin{array}{l}\text { Partial/incomplete description, unclear, } \\
\text { incorrectly applies theory constructs, not relevant } \\
\text { to population, issue, setting. } 1-7 \text { points }\end{array}$ & $\begin{array}{l}\text { Fails to provide any description of } \\
\text { storyline or characters, inadequate } \\
\text { description. } 0 \text { points }\end{array}$ \\
\hline Music and voice narration 5 points & $\begin{array}{l}\text { Excellent music and voice narration that } \\
\text { complements storyline, characters, topic. } 4-5 \text { points }\end{array}$ & $\begin{array}{l}\text { Choice of music and voice narration not } \\
\text { appropriate to storyline, characters. } 1-3 \text { points }\end{array}$ & $\begin{array}{l}\text { Fails to provide any description. } \\
0 \text { points }\end{array}$ \\
\hline $\begin{array}{l}\text { Style/Flow (Transition and Scenes Linking) } \\
5 \text { points }\end{array}$ & $\begin{array}{l}\text { Organized, sections clearly labeled, clear description } \\
\text { of characters, coherent storyline, references cited } \\
\text { properly (APA or MLA style). } 4-5 \text { points }\end{array}$ & $\begin{array}{l}\text { Sections omitted with no description why, } \\
\text { no labeling of sections, poor organization, } \\
\text { references cited incorrectly. 1-3 points }\end{array}$ & $\begin{array}{l}\text { Poorly constructed, disorganized, } \\
\text { major sections missing, referenced } \\
\text { material not cited. } 0 \text { points }\end{array}$ \\
\hline Lessons learned 3 points & Thorough and clear description. $2-3$ points & Partial/incomplete description. 1 point & $\begin{array}{l}\text { Fails to provide any description. } \\
0 \text { points }\end{array}$ \\
\hline \multicolumn{4}{|c|}{$\begin{array}{l}\text { Self-assessment of individual and group contributions and active participation. (out of } 5 \text { points) } \\
\text { Total out } 45 \text { points. Project grade: }\end{array}$} \\
\hline
\end{tabular}


in the study project workshop. Median age of the study group was 21 years, and 67 (55\%) were females. Most of the participants $(67 \%)$ were living in urban communities, while $23 \%$ were living in rural districts of the different governorates included.

\section{knowledge \\ Pre/post assessment of the students'}

Students were assessed for gaining knowledge concerning the topics included in the training packages, pre/posttest was used for evaluation and percent change of knowledge indicated an improvement in students' knowledge levels as shown in Figure 1.

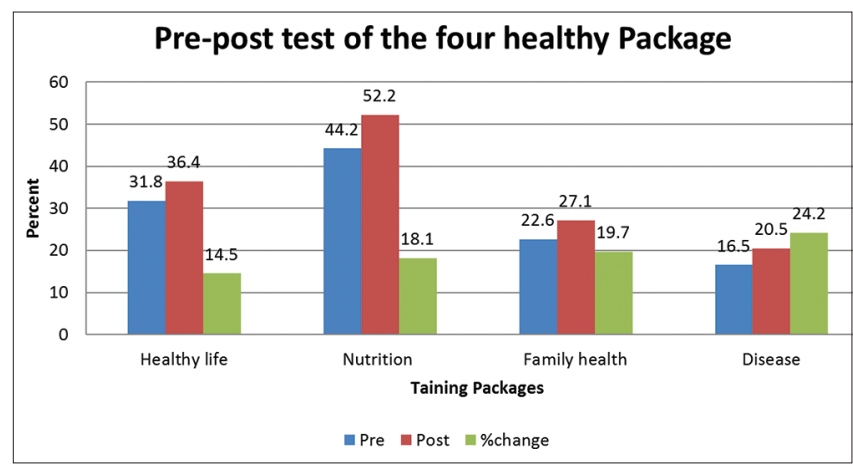

Figure 1: Pre- and post-test of the training package and percent change of knowledge

\section{Students' workshop evaluation}

A questionnaire was used for evaluation of the workshop included; level of achievement, topics included, scientific materials presented, duration, and timing of the program. Trainers' performance of presentation tools, information addressed by the lecturers, level of discussion and response to the participants' questions.

About half of the students indicated that the level of achievement was acceptable and more than one-quarter scored good level. In Figure 2, about 44\% of the participants indicated that the topics were very good and matched their expectations.

Almost half $(49 \%)$ of the students indicated that the quality of the scientific material was very good (Figure 3).

About $68 \%$ of them mentioned that the duration of the program was good, very good or excellent, reflecting the satisfaction of about two-thirds of the participants. One out of every three students expressed dissatisfaction with the timing of the training. Almost half of them scored trainer's performance as good, very good and excellent. Sixty three percent of the students acknowledged the training objectives and implementation.

Open-ended questions highlighted pros and cons of the program, the most important skills and

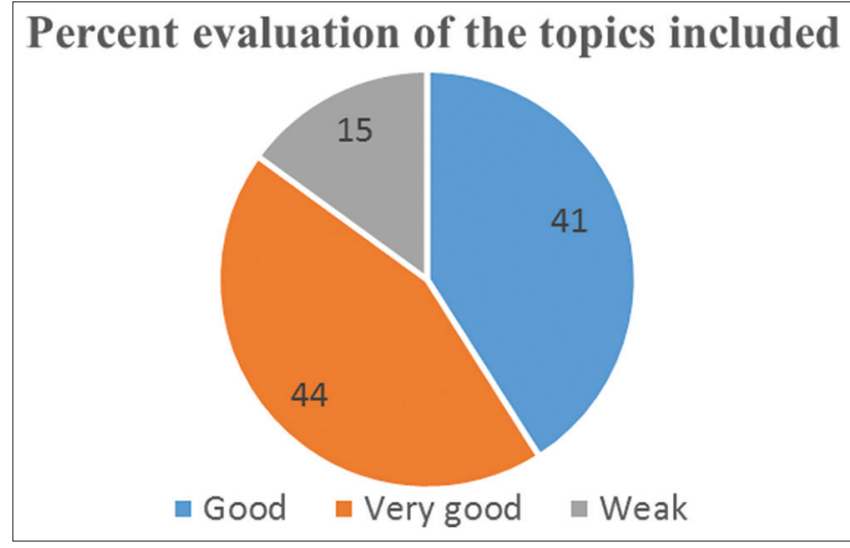

Figure 2: Students' evaluation for the topics included

knowledge gained, suggestions and recommendations mentioned by the students to maximize the use of this type of workshops in the framework of strengthening and activating the "EYI." Major Pros were exchanging experiences among participants and between governorates, establishing the concept of teamwork, increasing awareness of young people about population issues, how to collect information and data from official and reliable sources, promote the concept of community participation, development and communication among young people. The most important drawbacks mentioned were: "the program was intensive and needed more time" and "Timing of the workshop was during the academic year." Key knowledge gained were how to reach data sources and mange it, how to design methods for health education, preparing documentary and photographic films. The most important skills gained were mobile photography, how to prepare videos, how to criticize and express their opinion, and how to organize and control time. Finally, their suggestions and recommendations; more practical training and recreational activities must be included, more time to know about objectives and requirements before training, the need for more resources and equipment for easy implementation.

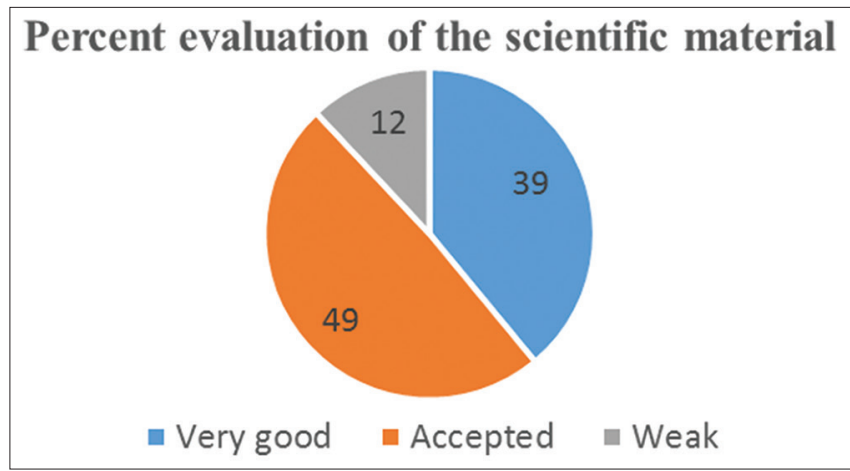

Figure 3: Students' evaluation for the scientific materials

\section{Students' video projects evaluation}

A communication for development UNICEF specialist guided the evaluation and editing of the students' projects. A video report was delivered based 
on items included in the evaluation rubric; the specialist comments, how commitment is the team for the general rules, selection of theory or model and technical skills, sound quality, music and voice narration, shifts between clips, and viewer fusion (Transition and Scenes Linking). In general, he evaluated the educational structure of the video, and the content of the health education message and how it relates to the presentation or treatment of the problem.

This evaluation has been done during students' 1-day workshop, points have been recorded for each video presented and an average score was calculated out of 45 points as shown in Table 2 . In addition, self-assessment, group contributions, and active participation were added in 5 points for each group. The first four videos have an average score of 38 (76\% of the total score) and the last four attached have an average score of 29 out of 50 points (58\% of the total score). Comments recorded during evaluation and recommendations for editing were considered in reference to the specialist. Furthermore, groups were willing to share tips and advice with other groups in terms of creating and editing the final video.

Using an open-ended format, students were asked to illustrate lessons learned. The majority (90\%) agreed that, "The DST project enhanced our understanding of diversity in the community and pushed us to explore topics that were difficult to talk about". Half of them (50\%) stated, "We feel more knowledgeable about different cultures which helped us to build research skills." Others (35\%) perceived the use of digital stories as a positive learning experience. One-fourth of the students added, "This project gives us the opportunity to grow and learn more as students". Almost 20\% declared, "One of the biggest challenges was also the biggest benefit; "working with a group and trying to diffuse interpersonal conflict gave me a better understanding of myself and how to influence group dynamics."

\section{Discussion}

DST is a valuable technology tool for use in educational settings as it entails researching, creating, analyzing, and combines visual images with written text [23]. It can be facilitated within groups or individuals by engaging participants in recording and sharing their lived experiences to educate others [24]. To preserve stories and strengthen community bonds, and to assist participants in deepening their understanding of their lives and circumstances [25]. One value from implementing this project was the potential of producing a video using mobile technology as an innovative tool for health promotion. The overall goal was to participate in the establishment of a network for medical students who can advocate and promote peer-to-peer education and community awareness sessions as a part of the initiative activities based on knowledge sharing, networking, and community engagement. It encourages the participants' students to create their own communications and use video documentation and clips as a powerful way to share and report experiences to others. It focuses on how medical students establish their voice through storytelling and exploring the use of digital technologies.

A previous research has recognized several effective health education interventions for promoting health behavior change [26]. These include pictures, narratives, and entertainment-education (E-E) which is a particularly successful application that involves the delivery of health messages by embedding them in entertainment media [27].

Our findings support the idea that videos and educational technologies have a great potential as culturally relevant health promotion tools. In the present study, four videos out of 8 achieved $76 \%$ of the total score according to the grading rubric used for evaluation, while the other 4 videos achieved $58 \%$ of the total score. Similarly, Lee and Priester (2015) [28] described the use of video as a way to involve communities in mutual experiences and dialogue about diversity. Especially noting the current global trend toward increasing production and use of smartphones and other mobile technology, video-based health education should ideally be optimized for mobile dissemination in the future, even if it is delivered using older platforms, such as university learning management systems, DVDs, offline tablets, or in-clinic television screens. However, for broad scaling of health education, it is important to easily adapt the content across different populations, platforms taking into consideration the cultural, socioeconomic, and language variations [29]. In this way, effective health communication related to primary health can be made more easily available and palatable to the target/rural/ marginalized/tribal population with good and sustained impact and at low cost [30].

The goal of designing content that is accessible and relevant to the needs and experiences of the end users has been crucial to our learning objective, which has led us to apply a HCD approach to the creation of our content and programs. Students learned also selected individual, interpersonal, community level, Social Behavioral Communication Change (SBCC) [19] theories and models. HCD entails empathy with the target population, collecting feedback together with responsive iteration. Similarly, Adam et al. (2019) [31] applied a HCD approach in their study bearing in mind that successful solutions should be targeted toward the needs of the end user in mind.

Alaska Natives and community health workers have used DST projects to promote positive youth development [32]. There have been several health promotion initiatives using digital stories or narratives as culturally appropriate tools to relay health information [33], [34]. 
A systematic review included 16 empirical studies focused solely on health professionals' learning as well as their behavior changes from DST. This review also illustrated the educational value of training individuals in the creation of digital stories as well as the benefits of including digital stories in conjunction with other learning activities [35].

As an educational tool, DST can facilitate a deeper engagement of students in the learning process. Moreover, digital stories can facilitate the dissemination of research findings in accessible and engaging ways, conveying key messages to promote the quality of care. In the present study, a positive feedback was obtained from students through the open-ended questions regarding the knowledge and skills they gained from DST. Similarly, Grant and Bolin (2016) stated an overall positive feedback from 96 undergraduate students as regards the DST project [36].

There is a growing trend to use storytelling as a research tool to extract information and/or as an intervention to effect change in the public knowledge, attitudes and behavior in relation to public health issues, primarily those with a strong element of disease prevention. However, evidence of its use in either or both capacities is limited. The study highlights the need for high-quality research on the impact of DST in health professionals' education and behaviors. In addition, the inclusion of qualitative, quantitative, and mixed method studies that will elucidate a comprehensive understanding of the breadth, usefulness, and limitations of digital storytelling as a method in health research.

\section{Limitations}

Although we have highlighted a range of benefits on the uses of DST in research, it is somewhat difficult to comment on how other researchers could attain the same benefits in future initiatives. Combination of the following factors contribute to making DST beneficial, participatory approach that makes DST meaningful for participants, clear communication and agreement regarding the use and dissemination of DSTs before commencing the project, taking steps to create a safe and respectful space in which to create DSTs, providing enough time and focused attention for each participant to craft their digital story, involving participants in each step of the research process from start to finish. Ensuring that such steps are taken makes it more likely that potential drawbacks of DST are avoided.

\section{Conclusions and Recommendations}

In the present study, students were successfully trained to produce a video for providing peer-to-peer and community health education. Since videos and educational technologies have a great potential as culturally relevant health promotion tools, it is recommended that DST can be widely used in Arab Open University for blending learning purposes. The COVID-19 pandemic is continuing to worsen, and more effective strategies are needed. Although digital media has played an important role, it should be further used to improve trust, build social solidarity, educate the public for prevention measures, and reduce the medical burden in facility-based sites.

\section{Acknowledgments}

We would like to thank all the members of EYI executive board who agreed to share their personal experiences through the digital storytelling process. IFMSA volunteers who participated in the study. This work was supported and executed in response to the Government of Egypt- United Nations Children's Fund (UNICEF), Country Program of Cooperation for 2016-2018.

\section{References}

1. World Health Organization. WHO Coronavirus Disease (COVID19). Geneva: World Health Organization. Available from: https:// covid19.who.int [Last accessed on 2021 Aug 01].

2. Gilliam M, Orzalli, S, Heathcock S, Sutherland E, Jagoda $P$, Menendez A, et al. From intervention to invitation: Reshaping adolescent sexual health through storytelling and games. Afr J Reprod Health 2012;16(2):189-96.

PMid:22916551

3. Suwardy T, Pan G, Seow PS. Using digital storytelling to engage student learning. Acc Educ. 2013;22(2):109-24. https://doi.org/1 0.1080/09639284.2012.748505

4. Papadopoulou S, loannis S. The emergence of digital storytelling and multimedia technology in improving Greek language teaching and learning: Challenges versus limitations. Sino US English Teach 2010;7(4):1-14.

5. Truong-White $\mathrm{H}$, McLean L. Digital storytelling for transformative global citizenship education. Can J Ed. 2015;38(2):1-28. https:// doi.org/10.2307/canajeducrevucan.38.2.11

6. Sondaal SF, Browne JL, Amoakoh-Coleman M, Borgstein A Miltenburg AS, Verwijs M. Assessing the effect of $m$ Health interventions in improving maternal and neonatal care in lowand middle-income countries: A systematic review. PLoS One. 2016;11(5):154-664. https://doi.org/10.1371/journal. pone.0154664

PMid:27144393

7. World Health Organization. WHO Compendium of Innovative health Technologies for Lowresource Settings, 2011-2014: Assistive Devices, eHealth Solutions, Medical Devices, other Technologies, Technologies for Outbreaks. Geneva, Switzerland: World Health Organization Press; 2014.

8. Toussaint DW, Villagrana, $M$, Mora-Torres $H$, de Leon $M$, Haughey, MH. Personal stories: Voices of Latino youth health 
advocates in a diabetes prevention initiative. Prog Community Health Partnersh. 2011;5(3):313-6. https://doi.org/10.1353/ cpr.2011.0038

\section{PMid:22080780}

9. Cumming GP, Currie HD, Moncur R, Lee AJ. Web- based survey on the effect of digital storytelling on empowering women to seek help for urogenital atrophy. Menopause Int. 2010;16(2):51-5. https://doi.org/10.1258/mi.2010.010004 PMid:20729493

10. Cueva M, Kuhnley R, Revels LJ, Cueva K, Dignan M, Lanier AP. Bridging storytelling traditions with digital technology. Int $\mathrm{J}$ Circumpolar Health. 2013;72:1. https://doi.org/10.3402/ijch. v72i0.20717 PMid:23984267

11. Dole S, Bloom L, Kowalske K. Transforming Pedagogy: Changing perspectives from teacher-centered to learnercentered. Interdiscip J Problem Based Learn. 2016;10(1):45-8.

12. Thesen A, Kara-Steriou J. Using digital storytelling to unlock student potential. NERA J. 2011;46(2):93-100.

13. Matthews J. Voices from the heart: The use of digital storytelling in education. Community Pract. 2014;87(1):28-30. PMid:24597059

14. Lyde AR. Health education field experience stories: A reflective, digital, performance-based project. J Health Educ Teaching. 2012;3(1):11-9

15. Kar SS, Premarajan KC, Ramalingam A, Iswarya $S$, Sujiv A, Subitha L. Selfdirected learning readiness among fifth semester MBBS students in a teaching institution of South India. Educ Health. 2014;27(3):289-92. https://doi. org/10.4103/1357-6283.152193 PMid:25758394

16. The National Population Strategy 2015-2030. Egypt: Ministry of Health and Population, Egypt National Population Council (NPC). Available from: http://www.npc.gov.eg/images/pdf [Last accessed on 2021 Apr 01].

17. United Nations Development Assistance Framework for Egypt 2013-2018. Available from: http://www.undp.org/content/dam/ egypt/docs/LegalFramework/UNDAF\%202013-2017.pdf [Last accessed on 2021 Jan 10].

18. Available from: http://www.www.ifmsa-Egypt.org.eg [Last accessed on 2021 Dec 25].

19. Figueroa ME, Kincaid DL, Rani M, Lewis G. Communication for Social Change: An Integrated Model for Measuring the Process and its Outcomes. The Communication for Social Change Working Paper Series No.1. New York: The Rockefeller Foundation; 2002.

20. EDHS. El-Zanaty and Associates. Egypt Demographic and Health Survey 2014; May 2014: Ministry of Health and Population, Egypt, The DHS Program ICF International; 2014.

21. Statistical Yearbook. Egypt: CAPMAS, Central Agency for Public Mobilization and Statistics, Egypt; 2016. Available from: http://arabdevelopmentportal.com/publication/egypt-figures2016-education [Last accessed on 2018 Feb 25].

22. World Medical Association Declaration of Helsinki. Available from: http://www.wma.net/en/30publications/10policies/b3/ index.html [Last accessed on 2021 Jan 01].

23. Cherry WR, Jr. Our place in the universe: The importance of story and storytelling in the classroom. Knowl Quest. 2017;46(2):50-5.

24. Laing CM, Moules NJ, Estefan A, Lang M. Stories take your role away from you: Understanding the impact on health care professionals of viewing digital stories of pediatric and adolescent/young adult oncology patients. J Pediatr Oncol Nurs. 2017;34(4):261-71. https://doi.org/10.1177/1043454217697023 PMid:28376686

25. Gubrium A, Fiddian-Green A, Lowe S, DiFulvio G, Peterson J. Digital storytelling as critical narrative intervention with adolescent women of Puerto Rican descent. Crit Public Health. 2019;29(3):290-301. https://doi.org/10.1080/09581596.2018.14 51622

PMid:31130780

26. Shaffer VA, Focella ES, Hathaway A, Scherer LD, Zikmund-Fisher BJ. On the usefulness of narratives: An interdisciplinary review and theoretical model. Ann Behav Med. 2018;52(5):429-42. https://doi.org/10.1093/abm/kax008 PMid:29684135

27. Shen F, Han J. Effectiveness of entertainment education in communicating health information: A systematic review. Asian $\mathrm{J}$ Commun. 2014;24(6):616-7. https://doi.org/10.1080/01292986. 2014.927895

28. Lee $\mathrm{O}$, Priester M. Increasing awareness of diversity through community engagement and films. J Soc Work Educ. 2015;51(1):35-46. https://doi.org/10.1080/10437797.2015.9771 26

29. Kratzke C, Cox C. Smartphone technology and apps: Rapidly changing health promotion. Glob J Health Educ Promot. 2012;15(1):15-16.

30. Bhattacharya S, Singh A, Marzo RR. Delivering emoji/icon-based universal health education messages through smartphones. AIMS Public Health. 2019;6(3):242-7. https://doi.org/10.3934/ publichealth.2019.3.242 [Last accessed on 2021 Jul 01]. PMid:31637274

31. Adam M, McMahon SA, Prober C, Barnighausen T. Humancentered design of video-based health education: An iterative, collaborative, community-based approach. J Med Internet Res. 2019;21(1):e12128. https://doi.org/10.2196/12128 PMid:30698531

32. Wexler L, Gubrium A, Griffin M, DiFulvio G. Promoting positive youth development and highlighting reasons for living in NorthwestAlaska through digital storytelling. Health PromotPract. 2013;14(4):617-23. https://doi.org/10.1177/1524839912462390 PMid:23099660

33. Lal S, Donnelly C, Shin J. Digital storytelling: An innovative tool for practice, education, and research. Occup Ther Health Care. 2015;29(1):54-62. https://doi.org/10.3109/07380577.2014.958888 PMid:25338054

34. Pérez M, Sefko JA, Ksiazek D, Golla B, Casey C Margenthaler JA, et al. A novel intervention using interactive technology and personal narratives to reduce cancer disparities. African American breast cancer survivor stories. J Cancer Surviv. 2014;8(1):21-30. https://doi.org/10.1007/s11764-013-0308-4 PMid:24030573

35. Moreau KA, Eady K, Sikora L, Horsley T. Digital storytelling in health professions education: A systematic review. BMC Med Educ. 2018;18:208. https://doi.org/10.1186/s12909-018-1320-1

36. Grant NS, Bolin BL. Digital storytelling: A method for engaging students and increasing cultural competency. J Effect Teaching. 2016;16(3):44-61. 